\title{
XLIII. On the electrical resistance of soft carbon under pressure
}

\section{T.C. Mendenhall}

To cite this article: T.C. Mendenhall (1886) XLIII. On the electrical resistance of soft carbon under pressure, Philosophical Magazine Series 5, 22:137, 358-363, DOI: $10.1080 / 14786448608627945$

To link to this article: http://dx.doi.org/10.1080/14786448608627945

曲 Published online: 29 Apr 2009.

Submit your article to this journal $[\pi$

Џll Article views: 4

Q View related articles $\square$ 


\section{[ 358 ]}

XLIII. On the Electrical Resistance of Soft Carbon under

Pressure. By T. C. Mendentali.*

A PAPER by the writer on "The Influence of Time on A the Change in the Resistance of the Carbon Disk of Edison's Tasimeter," was published in this Journal in July 1882 [Phil. Mag. for August, p. 115]. The object of the paper, as its title indicated, was to present the results of some experiments with the carbon disk which appeared to show that, when pressure was applied, the entire diminution of resistance did not take place at once, but that the reduction continued with diminished rapidity through a considerable period of time. At the conclusion of the paper brief reference was made to investigations of the same subject by $\mathrm{Mr}$. Herbert Tomlinson and by Professors Sylvanus P. Thompson and W. F. Barrett.

Only the conclusion reached by some of these physicists was at that time known to the writer, their verdict being that the observed diminution of resistance was really due to the better surface-contact of the electrodes, and not to any actual change in the specific resistance of the carbon itself.

The last paragraph in the paper contains the following :"Without knowing anything about the nature of these experiments, the writer desires to record his belief that this theory does not entirely account for the facts stated above."

This, certainly not too rash, declaration of belief in a true pressure-effect was the subject of decidedly unfavourable criticism in the columns of one or two European scientific journals ; and in this Journal of December 1882, Professor Sylvanus P. Thompson published an article entitled "Note on the alleged Change in the Resistance of Carbon due to Change of Pressure," which was an exceptionally severe criticism of the previous paper by the writer. In this article Professor Thompson refers to the investigations of Mr. Tomlinson, Prof. Barrett, and himself, and also to experiments made by Professors Naccari and Pagliani and Mr. Conrad W. Cooke, and he declares that, with the exception of Professor Mendenhall, all who have investigated the point are agreed in their verdict "that this alleged effect was due not to any change in the specific resistance of carbon, but to better external contact between the piece or pieces of carbon and the conductors in contact with them." The truth of this statement is the question at issue. It may be well to remark, however, that although Professor Thompson makes this assertion in December, Mr. Tomlinson had shown, nearly a year earlier, in a paper presented to the Royal Society, on the 26th of the previous January, that the

* From Silliman's American Journal for September, 1886. 
electrical resistance of hard carbon was diminished by pressure. The amount of the diminution is small, however, and he afterwards expresses the opinion that in such instruments as the microphone transmitter, the greater portion of the observed diminution in resistance is due to variation in surface contact.* Mr. Tomlinson's experiments were made with hard carbon, similar in character to that made use of in experiments to be described presently.

In the summer of 1884 , the writer communicated to the American Association for the Advancement of Science a brief account of experiments which satisfied him that the opinion which he had previously expressed concerning the nature of the phenomenon was unquestionably correct. Within the past year the subject has been taken up again, and by means of improved methods and instruments all doubts seem to have been removed.

Innumerable experiments made by physicists of many countries have established, beyond question, the fact that the electrical properties of matter are modified by stress and strain. In carbon the effect of pressure is to diminish resistance. For hard carbon this was established by the investigation of $\mathrm{Mr}$. Tomlinson. In compressed lampblack, as seen in Edison's disks, the effect is very great, and that this is for the most part a true pressure-effect is proved, it is believed, by the experiments about to be described.

In the beginning it was desirable to determine, roughly, the magitude of this effect in the case of hard carbon. For this purpose a copper-plated rod, such as is used in the are lamp, about 12 centim. in length and 1.5 centim. in diameter, was selected and its ends were ground flat at right angles to its axis. The plating was then removed, except that a band about 5 centim. in width was left near each end of the rod. Two cork rings 1.5 centim. thick were fitted to the rod, after which they were tnnnelled out on the inside, and a hole was made in each so that when they were in place over the copper bands, and mercury was poured in, it would flow around the ring tunnel and make a contact with the carbon as satisfactory as could be desired. The ends of the rod were protected by thin plates of vulcanite, and it was placed between the jaws of a vice. The current from a battery of two or three gravitycells was passed through the rod by plunging wires into the mercury cups formed by the corks. By this arrangement it was possible to apply pressure at the ends of the rod without in any way influencing the contacts through which the current passed.

* 'Nature,' March 16, 1882. 
The terminals of a reflecting-galvanometer whose resistance was about $5000 \mathrm{ohms}$ were also introduced into these mercury cups, and enough additional resistance was introduced to make a convenient deflection of the spot of light upon the scale. When all was adjusted and the spot of light was at rest, the pressure was applied by turning the handle of the vice. In every instance the deflection decreased, showing diminished resistance. This effect was not due to the heat produced by compression, as experiment proved that cause to be inadequate. It was found to be necessary to make the carbon rod decidedly warm to the touch in order to lower the resistance by the same amount; besides the effect was not transient, as would have been the case if it had been due to the change in temperature. It was also found that compression at right angles to the direction of the current produced a similar effect, but less in magnitude. These facts had been already announced by Mr. Tomlinson.

These experiments with hard carbon or with other rigid bodies are comparatively easy, as there is no difficulty in applying the pressure independent of the contact surfaces, so that possible variation of the latter need not be considered. Unfortunately it appears to be quite impossible to secure this arrangement in the examination of soft carbon. It cannot readily be obtained in forms different from the small disk or button in which it originally appeared, and it is so fragile that it requires the most careful manipulation. Under these circumstances, the only thing to do is to secure the best possible surface-contact of the poles to begin with. Perhaps the ideal arrangement would be a disk with its two opposite faces electroplated with copper, through which a contact with mercury can be secured. The electroplating of two opposite faces of a disk of compressed lampblack is a work of extreme difficulty, and so far as known to the writer has not yet been accomplished, although he is greatly indebted to $\mathrm{Mr}$. Edison for a serious and persistent effort to secure this result, none the less appreciated because, owing to the extremely fragile character of the disk, it proved to be unsuccessful.

It was therefore necessary to depend upon the contact of mercury with the surface of the carbon itself. As this was the contact employed by Professor Barrett in the experiment which Professor Thompson considered "crucial," its use can hardly be objected to in this instance.

The arrangements for the test of the soft carbon were as follows :-two glass tubes about 20 centim. in length were bent at one end into a quarter of a circumference, so that when the two were joined and the straight branches of the tube were 
in a vertical position the appearance was that of the letter " $U$," the height being about 15 centim. Near the lower end of each a short tube was sealed in, over which rubber tubing could be passed, and at the lower part of the curve, in each, a platinum wire was passed through and sealed. The ends of the tubes were ground flat, and they were mounted in such a way that while one was fixed in position, the other could be moved toward or away from it in one plane, and so that the ground ends of the curved parts were always exactly opposite to each other. The movable tube was then taken from its place, the ground edge of its curved end was coated with glue, and it was carefully brought down upon the upper surface of a carbon disk which rested in a horizontal plane. The glue causing the disk to adhere to the tube, the latter could then be secured to its sliding stand, ready to move into place. The ground edge of the fixed tube was now coated with glue, after which the novable tube holding the carbon disk was gently moved up until the disk pressed against the end of the other tube, the glue forming the junction. In this way a carbon wall or partition was formed between the two halves of a "U" tube. When the glue had hardened, mercury was introduced on both sides to a height sufficient to entirely cover the faces of the carbon disk. The current was introduced through the platinum electrodes, which plunged into mercury cups on either side.

In some of the earlier experiments variations of pressure were produced by the addition of mercury to the two branches of the tube, but vastly better than this was the method latterly used, in which the pressure of air was substituted for that of mercury. Glass plates were sealed on the open ends of the two upright branches, thus enclosing a space on each side, except at the small side tubes, to which short pieces of rubber tubing were attached. These were joined by means of a $\mathrm{T}$ tube, so that equality of pressure on both faces of the disk was secured.

The circuit consisted of the battery, the disk, and an additional resistance varying from $3 \mathrm{ohms}$ to $10 \mathrm{ohms}$ for purposes of comparison. The electric ends of the disk and of the resistance were joined to a specially arranged key, by means of which either could be connected with the terminals of a reflecting galvanometer whose resistance was about 7000 ohms. By means of the deflections of the needle of this galvanometer, the resistances were compared and variations noted, the arrangement being substantially the same as that previously used in the experiments with hard carbon. A pressure-gauge, sometimes of water, sometimes of mercury, was attached to

Phil. Mag. S. 5. Vol. 22. No. 137. Oct. 1886. 2 B 


\section{Electrical Resistance of Soft Carbon under Pressure.}

the apparatus to indicate variations in pressure, and these variations were generally produced by blowing from the mouth into a rubber tube about two metres in length. Very many experiments were made, all without exception showing great diminution in the resistance of the disk by increase of pressure; and it will be sufficient to quote a few of the results.

The disk is sufficiently sensitive to show very slight changes in atmospheric pressure. On closing the open end of the rubber tube, and slightly pressing any part of it between the thumb and finger, the spot of light instantly moved, showing decrease of resistance. A pressure measured by 5 millims. of water produced a decided effect. The resistance of the disk, with its mercury and platinum wire connections, under ordinary conditions was slightly greater than $6 \mathrm{ohms}$. A pressure measured by 5 centim. of mercury instantly reduced it to less than 3 ohms. If the pressure was maintained, a slow fall of resistance continued for a long time, as found in the previous investigation of the subject. If the initial pressure was small the recovery would be instantaneous on its removal ; but if it was large, so as to greatly reduce the resistance, it was found that the recovery would not be complete on the withdrawal of the pressure, sometimes falling short by as much as ten per cent., after which a slow rise would take place. This result is not quite in agreement with the statement made in the first paper upon this subject, which was based, however, upon a much less satisfactory series of experiments.

An examination was made of the effect of the strength of the current upon the resistance of the disk. The weakest current used was a little less than 001 ampere, and the strongest was about $\cdot 37$ ampere, so that one was approximately 400 times the other. Throughout this range no sensible differences in the resistance of the disk was observed, the agreement at the two extremes being within the errors of measurement. Under all conditions the effect of variations of pressure was the same.

The faces of a soft carbon disk are always smooth and polished ; the surface of hard carbon, on the contrary, is generally more or less rough and irregular. It would appear, therefore, that, if the reduction of the resistance of soft carbon by increase of pressure is due to better surface-contact, this reduction of resistance should be much more marked with hard than with soft carbon. Experiments already described showed that the effect of pressure on hard carbon was very small; so small, in fact, that the pressure of a few centimetres of mercury would hardly produce a sensible effect. 
The substitution of a disk of hard carbon for the soft, in the apparatus described, ought to show, then, whether any considerable part of the resistance-variations observed could be attributed to variation of contact between mercury and carbon. A disk of hard carbon similar in dimensions to the soft disk previously employed was accordingly inserted botween two similarly arranged tubes. The result of this experiment was to show, as had been anticipated, a small decrease of resistance when the pressure was increased. A pressure of about 7 centim. of mercury reduced the galvanometer-deflection from 36 to 35 divisions of the scale. This indicates a change of less than 3 per cent., resulting from a pressure which with the soft disk lowered the resistance by more than 60 per cent. There can be little doubt that this small reduction is due almost entirely to better surface-contact produced by pressure.

Throughout all of the experiments with soft carbon, it exhibited more or less irregularity in its behaviour. The application of a pressure very largely in excess of the maximum referred to above would sometimes result in a permanent reduction of the resistance of the disk, indicating that a permanent set had taken place. By the exercise of care, however, what may be called the "normal" resistance may be maintained fairly constant for a considerable length of time.

Conclusions. - When carbon is prepared in the form of compressed lampblack, its electrical resistance varies greatly with the pressure to which it is subjected. A small part of this variation is doubtless to be attributed to change in surface-contact between the carbon and the electrodes through which the current is introduced, but by far the larger part (provided any effort is made to secure good surface-contact) is due to a real change in the resistance of the carbon itself. The resistance of carbon in this condition is fluctuating and uncertain to a degree that seems to prevent its use as a factor in any device for the accurate measure of pressure.

\section{On Dew.}

To the Editors of the Philosophical Magazine and Journal. GenTlemen,

T $N$ the paper by Mr. Charles Tomlinson, F.R.S., in the 1 September number of your Journal, entitled "Further Remarks on Mr. Aitken's Theory of Dew," there is little of scientific interest, the points advanced being mostly of a controversial character. As, however, the whole tone of his 2 B 2 